\title{
Chronic Inguinal Pain After Kidney Transplantation, a Common and Underexposed Problem
}

\author{
Marcel Zorgdrager ${ }^{1} \cdot$ Johan. F. M. Lange $^{1} \cdot$ Christina. Krikke $^{1} \cdot$ \\ Gertrude. J. Nieuwenhuijs ${ }^{2}$ - Sybrand. H. Hofker ${ }^{1}$. \\ Henri. G. D. Leuvenink ${ }^{1} \cdot$ Robert A. Pol $^{1}$
}

Published online: 16 September 2016

(c) The Author(s) 2016. This article is published with open access at Springerlink.com

\begin{abstract}
Background The incidence and impact of chronic inguinal pain after kidney transplantation is not clearly established. A high incidence of pain after inguinal hernia repair, a comparable surgical procedure, suggests an underexposed problem.

Methods Between 2011 and 2013, 403 consecutive patients who underwent kidney transplantation were invited to complete the Caroline Comfort Scale (CCS) and Visual Analog Scale (VAS) in order to assess the incidence of chronic inguinal pain and movement disabilities, complemented by questions regarding comorbidity during followup.

Results The response rate was $58 \%(n=199)$ with a median follow-up of 22 months (IQR 12-30). In total, 90 patients $(45 \%)$ reported a CCS $>0$ and 64 patients $(32 \%)$ experienced at least mild but bothersome complaints. Most inguinal complaints were reported during bending over and walking with a mean CCS score of $1.1(\mathrm{SD} \pm 2.2)$ and $1.2(\mathrm{SD} \pm 2.4)$, respectively. A high body mass index (BMI), delayed graft function, and the need for a second operation were associated with a higher CCS score on univariate analysis. Using multivariate analysis, only BMI $(p=0.02)$ was considered an independent risk factor for chronic inguinal pain.

Conclusions The incidence of chronic inguinal pain is a common though underexposed complication after kidney transplantation. More awareness to prevent neuropathic pain seems indicated.
\end{abstract}

Robert A. Pol

pol.chirurgie@gmail.com; r.pol@umcg.nl

Marcel Zorgdrager

marcelzorgdrager@online.nl

Johan. F. M. Lange

j.lange@umcg.nl

Christina. Krikke

c.krikke@umcg.nl

Gertrude. J. Nieuwenhuijs

g.j.nieuwenhuijs-moeke@umcg.nl

Sybrand. H. Hofker

h.s.hofker@umcg.nl
Henri. G. D. Leuvenink

h.g.d.leuvenink@umcg.nl

1 Department of Surgery, Division of Transplant Surgery, University Medical Center Groningen, University of Groningen, P.O. Box 30 001, 9700 RB Groningen, The Netherlands

2 Department of Anesthesiology, University Medical Center Groningen, University of Groningen, Groningen, The Netherlands 


$\begin{array}{ll}\text { Abbreviations } \\ \text { CCS } & \text { Carolina Comfort Scale } \\ \text { VAS } & \text { Visual Analog Scale } \\ \text { IQR } & \text { Interquartile range } \\ \text { BMI } & \text { Body mass index } \\ \text { QoL } & \text { Quality of life } \\ \text { ASA } & \text { American Society of Anaesthesiologists } \\ \text { CCI } & \text { Charlson Comorbidity Index } \\ \text { NPRS } & \text { Numeric pain rating scale } \\ \text { SD } & \text { Standard deviation } \\ \text { DGF } & \text { Delayed graft function } \\ \text { NODAT } & \text { New onset diabetes after transplantation } \\ \text { DM } & \text { Diabetes mellitus } \\ \text { COPD } & \text { Chronic obstructive pulmonary disease } \\ \text { EM } & \text { Expectation maximization } \\ \text { MI } & \text { Multiple imputation }\end{array}$

\section{Introduction}

Kidney transplantation remains the preferred treatment in patients with end-stage renal disease and not only results in a better survival but also in an improved quality of life (QoL) [1, 2]. QoL is strongly influenced by (chronic) pain and the incidence after kidney transplantation is estimated as high as $62 \%$ [3]. The etiology of this chronic pain, however, is largely unknown.

Inguinal herniorrhaphy, a surgical procedure located in comparable anatomical levels in the inguinal region, is known for its high risk (15-53\%) of chronic pain [4]. Herein three types of chronic pain are described in the literature: somatic, neuropathic, and visceral pain [5]. Several techniques, approaches, and hypothesis have been formulated to minimize the risk of developing chronic pain. First, the type of mesh used appears to play a role in developing chronic pain after inguinal hernia repair [6]. Second, the proper identification of the three inguinal nerves appears to prevent neuropathic chronic pain [4]. During incision and dissection, the ilioinguinal and iliohypogastric nerves are first encountered in the superficial preperitoneal surgical plane (Fig. 1), and at the deep retroperitoneal level, all three nerves can be identified within the surgical space (Fig. 2). Thirdly, prophylactic neurectomy is considered an option when the risk of chronic inguinal pain is expected to be high [7].

A large Dutch study among surgeons and surgical residents showed a reduced understanding of inguinal neurologic anatomy and an underestimation of the chronic inguinal pain incidence after hernia repair [8]. Because of the comparable anatomical approach during kidney transplantation, we hypothesized that the chronic pain after

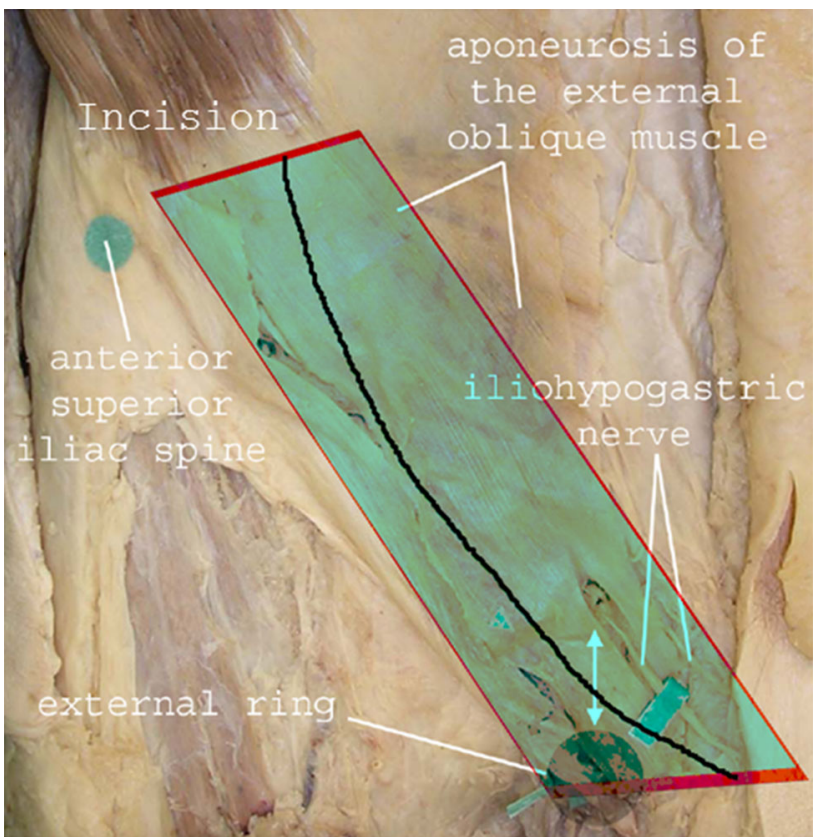

Fig. 1 Preperitoneal or superficial surgical layer is shown. At this level, the iliohypogastic and ilioinguinal nerves are at risk. The ilioinguinal nerve is located parallel to the inguinal ligament and deep to the internal oblique aponeurosis (both not shown)

transplantation has a similar etiology and is a relatively underexposed problem. To assess this theory, we performed a cohort analysis with emphasis on inguinal chronic pain in kidney transplant patients.

\section{Patients and methods}

Between 2011 and 2013, 403 consecutive patients who underwent kidney transplantation were invited to complete the questionnaires [9]. These data were added to a large prospective database of kidney transplant patients. Exclusion criteria were combined kidney/pancreas transplantation, transplantation through a midline laparotomy, age $<18$ years, incapability to fill out the questionnaire (e.g., intellectual disability or foreign language), and death during follow-up. There was no upper limit of BMI for performing kidney transplantation in our center; patients with a BMI of $>35$ were discussed in a multidisciplinary panel consisting of nephrologists and surgeons where the safety and technical feasibility were determined. Informed consent was obtained from all included patients.

\section{Transplantation procedure}

An oblique surgical incision was performed from the pubic bone through about two centimeters cranial to the superior 
Fig. 2 Retroperitoneal space is shown. All three nerves are identified within the preparation space and are at risk during dissection

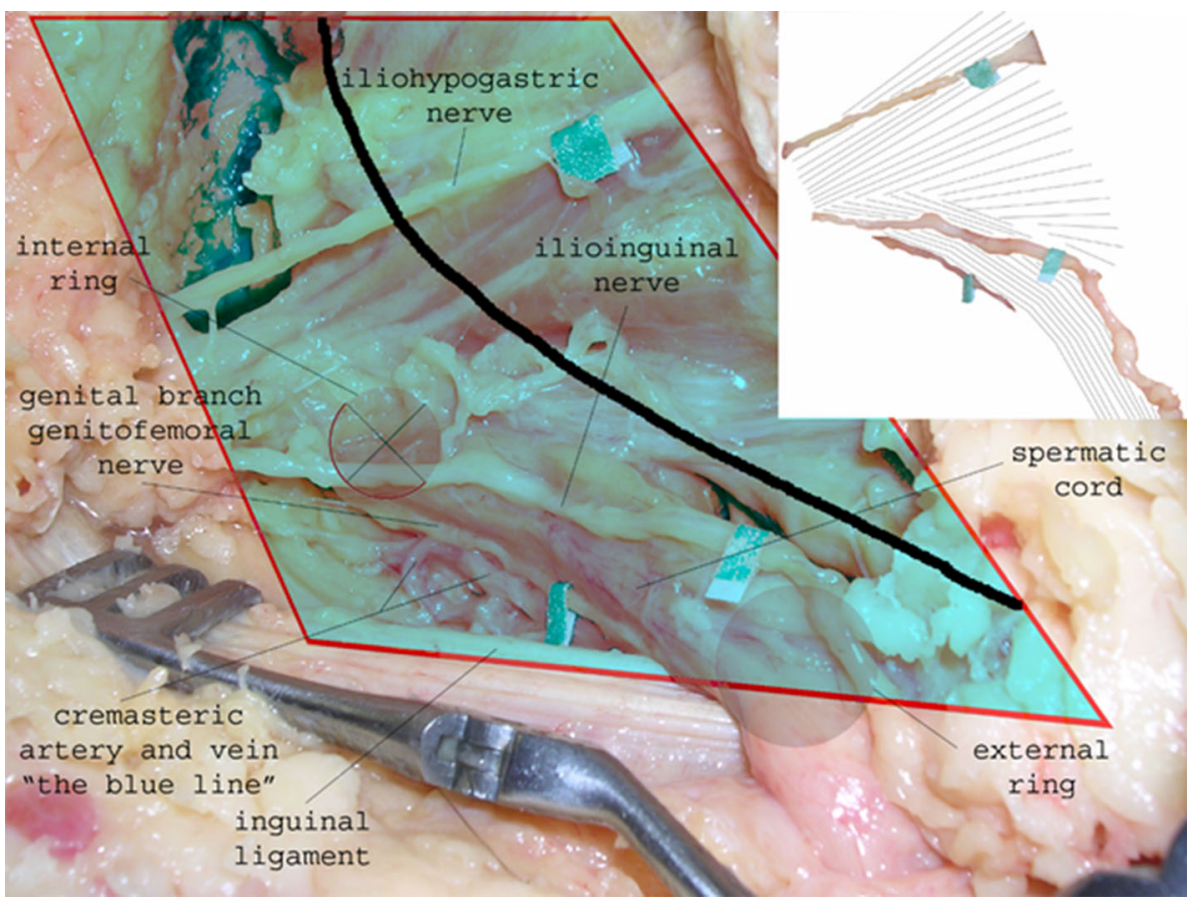

anterior iliac spine. The internal and external oblique fasciae were closed by dissolvable polydioxanone sutures, and the skin was closed by staples. Postoperative pain management consisted of paracetamol and administration of piritramide (Dipidolor ${ }^{\mathbb{B}}$ ) intravenously or subcutaneously. A patient-controlled analgesia pump was occasionally used. Nonsteroidal anti-inflammatory drugs were avoided because of nephrotoxic side effects. The postoperative pain treatment during the first $24 \mathrm{~h}$ was evaluated by anesthetists.

\section{Clinical data selection}

Collected data consisted of age, gender, body mass index (BMI; weight in $\mathrm{kg} / \mathrm{height}$ in meters squared), American Society of Anaesthesiologists (ASA) score, complications according to Clavien-Dindo classification (within 30 days after transplantation), type of graft, site of transplantation, need for re-intervention, need for transplantectomy, and allograft rejection. Comorbidity was determined by the age-adjusted Charlson Comorbidity Index (CCI), based on the previous medical history. The CCI is a weighted score which predicts the 1-year mortality of a patient, based on coexisting medical conditions and age [10].

For completeness, we added general questions to the enquiry to assess potential confounding factors. For example, $90 \%$ of diabetic patients develop polyneuropathy at some time and this could lead to bias [11]. Furthermore, patients with chronic obstructive pulmonary disease are known to have a high incidence of chronic pain in general [12].

\section{Questionnaire}

The questionnaire consisted of the Carolina Comfort Scale (9), the Visual Analog Scale (VAS-scale) [13], the Numeric Pain Rating Scale (NPRS-scale) [14], and a few questions aimed at their medical history and use of analgesics (Appendix). The CCS was originally validated for pain assessment after inguinal hernia repair with use of a mesh [9]. For this study, we modified the CCS to kidney transplantation in which the mesh-related questions were removed (Table 1). Instead, patients were asked if they experienced any inguinal pain or limited range of motion when certain activities are performed. After the first request to participate, all non-repliers were contacted by telephone in order to obtain the results. A previous study, which validated the questionnaires in a Dutch population of patients with inguinal hernia, reported $60 \%$ response rate [9]. Because response rate in a population of chronic kidney disease is likely to be lower, the minimum response rate was set at $50 \%$. Chronic inguinal pain was defined as any patient who suffered from inguinal complaints $\geq 3$ months after surgery, in accordance with hernia repair surgery [5]. Patients who scored a CCS $\geq 2$ on one of the subcategories were considered as patients with significant and bothersome inguinal complaints. 
Table 1 Modified Carolina Comfort Scale

\begin{tabular}{|c|c|c|c|c|c|c|c|}
\hline \multicolumn{8}{|c|}{ While lying down, do you have } \\
\hline Pain & 0 & 1 & 2 & 3 & 4 & 5 & $\mathrm{n} / \mathrm{a}$ \\
\hline \multicolumn{8}{|c|}{ While bending over, do you have } \\
\hline Pain & 0 & 1 & 2 & 3 & 4 & 5 & $\mathrm{n} / \mathrm{a}$ \\
\hline $\begin{array}{l}\text { Movement } \\
\text { limitations }\end{array}$ & 0 & 1 & 2 & 3 & 4 & 5 & $\mathrm{n} / \mathrm{a}$ \\
\hline \multicolumn{8}{|c|}{ While sitting up, do you have } \\
\hline Pain & 0 & 1 & 2 & 3 & 4 & 5 & $\mathrm{n} / \mathrm{a}$ \\
\hline $\begin{array}{l}\text { Movement } \\
\text { limitations }\end{array}$ & 0 & 1 & 2 & 3 & 4 & 5 & $\mathrm{n} / \mathrm{a}$ \\
\hline \multicolumn{8}{|c|}{ While performing activities of daily life, do you have } \\
\hline Pain & 0 & 1 & 2 & 3 & 4 & 5 & $\mathrm{n} / \mathrm{a}$ \\
\hline $\begin{array}{l}\text { Movement } \\
\text { limitations }\end{array}$ & 0 & 1 & 2 & 3 & 4 & 5 & $\mathrm{n} / \mathrm{a}$ \\
\hline \multicolumn{8}{|c|}{ While coughing or deep breathing, do you have } \\
\hline Pain & 0 & 1 & 2 & 3 & 4 & 5 & $\mathrm{n} / \mathrm{a}$ \\
\hline $\begin{array}{l}\text { Movement } \\
\text { limitations }\end{array}$ & 0 & 1 & 2 & 3 & 4 & 5 & $\mathrm{n} / \mathrm{a}$ \\
\hline \multicolumn{8}{|c|}{ While walking, do you have } \\
\hline Pain & 0 & 1 & 2 & 3 & 4 & 5 & $\mathrm{n} / \mathrm{a}$ \\
\hline $\begin{array}{l}\text { Movement } \\
\text { limitations }\end{array}$ & 0 & 1 & 2 & 3 & 4 & 5 & $\mathrm{n} / \mathrm{a}$ \\
\hline \multicolumn{8}{|c|}{ While walking up the stairs, do you have } \\
\hline Pain & 0 & 1 & 2 & 3 & 4 & 5 & $\mathrm{n} / \mathrm{a}$ \\
\hline $\begin{array}{l}\text { Movement } \\
\text { limitations }\end{array}$ & 0 & 1 & 2 & 3 & 4 & 5 & $\mathrm{n} / \mathrm{a}$ \\
\hline \multicolumn{8}{|c|}{ While exercising, do you have } \\
\hline Pain & 0 & 1 & 2 & 3 & 4 & 5 & $\mathrm{n} / \mathrm{a}$ \\
\hline $\begin{array}{l}\text { Movement } \\
\text { limitations }\end{array}$ & 0 & 1 & 2 & 3 & 4 & 5 & $\mathrm{n} / \mathrm{a}$ \\
\hline
\end{tabular}

0 no symptoms, 1 mild but not bothersome symptoms, 2 mild and bothersome symptoms, 3 moderate and/or daily symptoms, 4 severe symptoms, and 5 disabling symptoms

\section{Statistical analysis}

Categorical variables were analyzed by means of the $\chi^{2}$ test or Fisher's exact test and presented as numbers or percentages presented as mean \pm standard deviation (SD). Continuous variables were tested with the Student's $t$ test for normal distribution and the Mann-Whitney $U$ test for skewed distribution and presented as median \pm interquartile range (IQR).

Linear regression method was used to perform univariate and multivariate analyses on factors associated with a higher score. Missing values were evaluated by Little's MCAR test and, depending of level of significance, missing data were replaced by either expectation maximization technique (EM) or multiple imputation regression method (MI). Two-tailed $\mathrm{P}$ values were used throughout and significance was set at $p<0.05$. All statistical analyses were done with the Statistical Package for the Social Sciences (SPSS 21.0, SPSS, Chicago, IL, USA, 2012).

\section{Results}

From 2011 to 2013, 403 consecutive patients underwent kidney transplantation. Based on before-mentioned exclusion criteria, 58 patients were excluded due to death during follow-up $(n=24)$, median laparotomy $(n=12)$, incapability of reading Dutch or English $(n=6)$, mental retardation or neurological deficit $(n=11)$, and patients who underwent two kidney transplantations within the study period $(n=5)$. Of the 345 remaining patients, 199 patients returned the questionnaire (58\%) of which 82 were female (41\%) and 116 were male (59\%). The median follow-up was 22 months (IQR 12-30). In total, $86 \%$ of participants completed the questionnaire resulting in $97 \%$ of items being answered. In Table 2, the patient characteristics are shown.

\section{Outcomes Carolina Comfort Scale}

The mean score of all patients was 6.9 (SD \pm 12.5 , range 0-55). In total, 90 patients (45\%) reported a CCS $>0$ and 64 patients $(32 \%)$ experienced bothersome complaints $(\mathrm{CCS} \geq 2)$ on one or more subcategories of the CCS. Bothersome movement impairments occurred in 54 patients $(27 \%)$. Most inguinal complaints were reported during bending over and walking with a mean CCS score of $1.1(\mathrm{SD} \pm 2.2)$ and 1.2 ( $\mathrm{SD} \pm 2.4)$, respectively. Mean outcomes are shown in Fig. 3.

Using univariate analysis, BMI $(p=0.01)$, need of a second operation $(p=0.038)$, and DGF $(p=0.033)$ were associated with a higher CCS score. In multivariate analysis, BMI $(p=0.02)$ remained an independent factor associated with a higher CCS score. (Table 3). The length of follow-up was not associated with a lower CCS score $(p=0.271)$.

All patients were asked to answer additional questions concerning their comorbidity and use of analgesics. Eleven percent of patients had ipsilateral inguinal surgery prior to or after the kidney transplantation. The incidence rates of chronic obstructive pulmonary disease and diabetes was 6.5 and $27.6 \%$, respectively. About $50 \%$ of the diabetic patients were new onset diabetes after transplantation (NODAT). Eleven percent of all patients used analgesics for inguinal complaints at time of completing the survey after a mean follow-up of 21.7 months ( $\mathrm{SD} \pm 11.3$ ). Despite these possible confounding factors, no differences in incidence of chronic pain could be found during sensitivity analysis when excluding patients with diabetes, COPD, or prior inguinal surgery. 
Table 2 Patient characteristics

\begin{tabular}{|c|c|}
\hline Variable & $N$ patients \\
\hline Age (years) & 53 (SD 12.4) \\
\hline \multicolumn{2}{|l|}{$\operatorname{Sex}$} \\
\hline Male & $117(58.8 \%)$ \\
\hline Female & $82(41.2 \%)$ \\
\hline BMI & $\begin{array}{l}26.3 \text { (SD 3.95) } \\
\text { (Range 15.8-40.4) }\end{array}$ \\
\hline Median ASA classification & 3 (IQR 2-3) \\
\hline Median CCI & 4 (IQR 3-5) \\
\hline \multicolumn{2}{|l|}{ Cause of kidney failure } \\
\hline Polycystic kidney disease & $43(21.6 \%)$ \\
\hline (Hypertensive) nephrosclerosis/FSGS & $35(17.6 \%)$ \\
\hline IgA nephropathy/Henoch-Schönlein & $27(13.6 \%)$ \\
\hline Unknown origin & $19(9.5 \%)$ \\
\hline Autoimmune mediated & $19(9.5 \%)$ \\
\hline Diabetic nephropathy & $15(7.5 \%)$ \\
\hline Glomerulonephritis, pathy & $11(5.5 \%)$ \\
\hline Urological & $9(4.5 \%)$ \\
\hline Renal agenesis/renal atrophy & $9(4.5 \%)$ \\
\hline Vascular/ischemic & $6(3.0 \%)$ \\
\hline (Medical) drugs & $6(3.0 \%)$ \\
\hline \multicolumn{2}{|l|}{ Pre-emptive transplantation } \\
\hline Yes & $58(29.1 \%)$ \\
\hline No & $141(70.9 \%)$ \\
\hline \multicolumn{2}{|l|}{ Type of donor } \\
\hline Living related & $55(27.6 \%)$ \\
\hline Living unrelated & $59(29.6 \%)$ \\
\hline DCD & $46(23.1 \%)$ \\
\hline DBD & $39(19.6 \%)$ \\
\hline \multicolumn{2}{|l|}{ Side donor nephrectomy } \\
\hline Right & $66(33.2 \%)$ \\
\hline Left & $130(65.3 \%)$ \\
\hline Unknown & $3(1.5 \%)$ \\
\hline \multicolumn{2}{|l|}{ Fossa recipient } \\
\hline Right & $160(80.4 \%)$ \\
\hline Left & $39(19.6 \%)$ \\
\hline Complications within 30 days & $111(55.8 \%)$ \\
\hline Clavien-Dindo grade III-IV & $63(56.8 \%)$ \\
\hline Need for reoperation & $11(9.9 \%)$ \\
\hline DGF & $54(27.1 \%)$ \\
\hline Allograft rejection & $35(17.6 \%)$ \\
\hline Transplantectomy & $4(2.0 \%)$ \\
\hline Median follow-up in months & 22 (IQR 12-30) \\
\hline
\end{tabular}

Patient characteristics. BMI body mass index, ASA American Society of Anaesthesiologists, CCI Charlson Comorbidity Index Score, FSGS focal segmental glomerulosclerosis, $D C D$ donation after cardiac death, $D B D$ donation after brain death, $D G F$ delayed graft function, Clavien-Dindo grade III-IV any complication which requires surgical, endoscopic, or radiological intervention

\section{VAS and NPRS scales}

The mean VAS score was $10(\mathrm{SD} \pm 20.1)$ and mean NPRS was $1.2 / 10(\mathrm{SD} \pm 2.0)$.

Fifty-one percent of the patients had a VAS $>0$ and $39 \%$ had NPRS $>0$ at the time of the survey. The ageadjusted CCI was associated with a higher VAS score $(p=0.007)$. DGF was associated with a higher NPRS score $(p=0.032)$ All other factors, including BMI, were nonsignificant in both scales.

\section{Discussion}

This study shows that $32 \%$ of patients suffer from chronic inguinal pain or impaired range of movement after kidney transplantation. The most important predictor of chronic inguinal pain after kidney transplantation in this study was BMI, which proved independent of known confounders as DM, COPD, and previous hernia surgery. Previous studies have reported a similar association between chronic pain and BMI after inguinal herniorrhaphy $[15,16]$. This finding seems to indicate that inguinal herniorrhaphy and kidney transplantation have a similar etiology regarding chronic pain.

Identification of the nerves reduces the chance of iatrogenic damage and chronic pain. Also, when accidentally a nerve gets injured despite this nerve minded attitude it can still be recognized and a decent neurectomy can be performed to prevent a neurinoma. Previous studies have already shown that detection is feasible during inguinal herniorrhaphy when adequate anatomical knowledge is present, which provides opportunities during kidney transplantation [17, 18]. Inguinal hernia surgery has learned that regarding pain, preoperative identification of the nerves has better results than neglecting the nerves $[19,20]$. But there is no evident difference between sparing of the nerves and standard neurectomy [21, 22]. However, considering the caused numbness identification is preferred. In kidney transplantation, the nerves will be identified more proximal, and therefore, neurectomy could additionally lead to motoric dysfunction of the oblique muscles of the abdominal wall [23]. Therefore, the authors advocate to spare the nerves after identification and only perform a neurectomy when there is suspicion of iatrogenic injury.

During kidney transplantation, no conscious detection of these nerves is generally performed, which may be an explanation for the high incidence of chronic inguinal pain. Whether detection of the nerves in kidney transplantation is sensible and wise cannot be concluded based on our results. 
Fig. 3 Mean outcomes of modified Carolina Comfort Scale for all eight subcategories

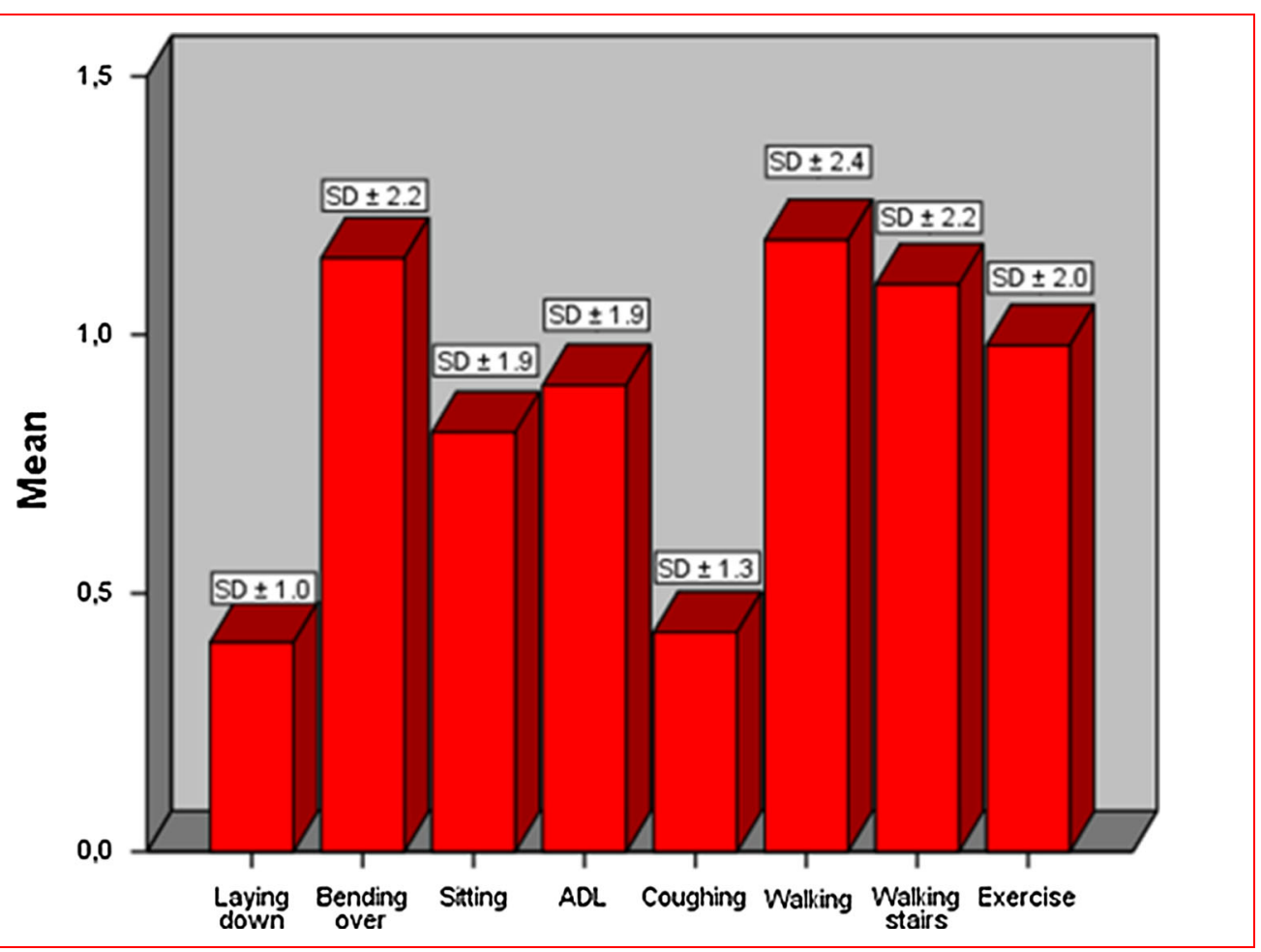

Table 3 Univariate and multivariate analyses

\begin{tabular}{lcllllllll}
\hline & Lying down & Bending over & Sitting & ADL & Coughing & Walking & Walking stairs & Exercise & Total CCS \\
\hline \multicolumn{2}{l}{ Univariate analysis } & & & & & & & & \\
BMI & 0.088 & $\mathbf{0 . 0 1 3}$ & $\mathbf{0 . 0 2 6}$ & 0.139 & $\mathbf{0 . 0 3 0}$ & $\mathbf{0 . 0 4 4}$ & $\mathbf{0 . 0 4 4}$ & $\mathbf{0 . 0 0 3}$ & $\mathbf{0 . 0 1 0}$ \\
DGF & 0.102 & 0.088 & $\mathbf{0 . 0 1 4}$ & $\mathbf{0 . 0 4 0}$ & 0.284 & $\mathbf{0 . 0 2 4}$ & $\mathbf{0 . 0 1 1}$ & 0.864 & $\mathbf{0 . 0 3 3}$ \\
Second OK & 0.267 & $\mathbf{0 . 0 1 3}$ & 0.078 & 0.184 & $\mathbf{0 . 0 0 1}$ & $\mathbf{0 . 0 3 5}$ & 0.096 & 0.729 & $\mathbf{0 . 0 3 8}$ \\
Multivariate analysis & & & & & & & \\
BMI & 0.137 & $\mathbf{0 . 0 2 4}$ & $\mathbf{0 . 0 4 1}$ & 0.188 & 0.061 & 0.066 & 0.069 & $\mathbf{0 . 0 0 3}$ & $\mathbf{0 . 0 1 0}$ \\
DGF & 0.156 & 0.184 & $\mathbf{0 . 0 2 2}$ & $\mathbf{0 . 0 4 0}$ & 0.443 & $\mathbf{0 . 0 2 4}$ & $\mathbf{0 . 0 1 1}$ & 0.930 & 0.053 \\
Second OK & 0.418 & $\mathbf{0 . 0 2 4}$ & 0.172 & 0.254 & $\mathbf{0 . 0 0 1}$ & 0.056 & 0.151 & 0.971 & 0.066 \\
\hline
\end{tabular}

Bold values are statistically significant

Univariate and multivariate analyses of variables associated with the different categories of the Carolina Comfort Scale (CCS)

$B M I$ body mass index, $D G F$ delayed graft function, $A D L$ activities of daily life, and only BMI was considered as an independent factor associated with a higher CCS score

Perhaps awareness of the etiology and incidence is a first step and additionally will result in better patient education. Given the risk in obese patients, an appropriate identification will be challenging. And, extending the duration of surgery will lead to a prolonged ischemia time with the associated risk of complications. However, with adequate anatomical knowledge the detection appears to be not time-consuming, and preventing pain will have a significant effect on retaining quality of life [17]. Therefore, we would carefully suggest that identifying the inguinal nerves should be performed during transplantation, especially in high-risk patients, and when perioperative iatrogenic damage is suspected, a surgical neurectomy should be considered.

A third of the patients with chronic inguinal pain do not receive any pain treatment which increases the need of healthcare services [3]. Our study showed a similar outcome, in which only $24 \%$ of patients with inguinal complaints used targeted painkillers. This might be caused by the interactions with immunosuppressive therapies which often limit the use of specific analgesics. We believe that this under treatment could be prevented by a more intensive support from the primary treating physician in 
conjunction with a pain specialists and pharmacists. Furthermore, the use of regional nerve blockade could be an additional method of pain relief in the first hours/days after surgery [24].

The incidence of chronic pain in general in patients with end-stage renal disease is one of the highest of all chronic diseases and is reported up to $30-50 \%$ of patients receiving hemodialysis [3]. After transplantation, this incidence will remain the same but the location seems to change, most likely caused by the immunosuppressive or antirejection therapy and the inguinal pain after the kidney transplantation. Previous studies have shown that $50 \%$ of kidney recipients experience pain at more than one location $[3,25]$. To assess this possible bias, we specifically asked all patients to describe the anatomical location where they experienced the most pain. In total, 118 of 199 (59\%) patients have answered this question and 53 of $118(45 \%)$ experienced the most pain in the inguinal region. When performing a sensitivity analysis with patients who experienced the most pain in inguinal region, both BMI as the need of re-operation were still significantly associated with a higher CCS score.

The relation between BMI and chronic pain is a widely known association and it seems to be a multifactorial phenomenon based on both psychosocial and biological factors [26]. One of the biological factors could be endocrine changes in fatty tissues which are characterized by a low-grade systemic inflammation. This could impair the pain modulation and lead to a lower pain threshold. The combination of these factors with surgical trauma and increased wound tension could be an explanation for increased chronic inguinal pain in obese patients.

This study has a few limitations that need to be addressed. First, about $11 \%$ of patients underwent ipsilateral inguinal surgery prior or after transplantation. To correct for this confounder, we performed a sensitivity analysis in which we excluded these patients which yielded the same results. Secondly, the response rate was only $58 \%$. We are fully aware this could have led to selection bias. All non-responders were contacted by phone and reasons varied from recent illness to participation in many other studies. Absence of chronic inguinal pain was incidentally given as a reason not to participate. The study which validated the questionnaire in a rather healthy hernia population reported a $60 \%$ response rate [9]. Therefore, we believe our study cohort is a good representative for the kidney recipients' population, and the incidence of chronic pain is not overestimated.

Thirdly, because some patients already suffered from atypical chronic pain, this may have influenced our results. A previous study reported that the presence of preoperative pain is an independent factor for chronic pain after inguinal herniorrhaphy [27]. However, in our study the incidence of chronic inguinal pain in patients with pre-emptive transplantation was comparable with patients who already received some form of renal placement therapies $(p=0.631)$, and allograft rejection was not associated with a higher score.

A higher age-adjusted CCI score was associated with a higher VAS score and DGF was associated with a higher NPRS score. However, both scales are unidimensional and therefore do not seem the most suitable to use after kidney transplantation.

A new prospective study should be performed to assess whether nerve identification in kidney transplantation is feasible and leads to a decrease in chronic pain.

\section{Conclusion}

Chronic inguinal neuropathic pain after kidney transplantation is common and seems to have a similar etiology as observed in inguinal hernia repair. Detection of the inguinal nerves is advised after hernia repair and leads to a decrease in chronic pain and improved quality of life. The same approach may be considered during kidney transplantation although it is unclear whether the same positive effects are obtained. This study intends to increase awareness among kidney transplantation surgeons in order to properly inform kidney recipient, especially obese patients, about the risk of chronic pain and consider appropriate measures.

Authors' contribution Marcel Zorgdrager: conceived of the study and its design, acquired the data, and was involved in data analysis and interpretation and writing the manuscript; Johan F. M. Lange, Christina Krikke, Sijbrand H. Hofker, Henri G. D. Leuvenink: were involved in data analysis and interpretation and contributed to the final adjustments to the manuscript after revising it critically for intellectual content; Gertrude J. Nieuwenhuijs: contributed to the final adjustments to the manuscript after revising it critically for intellectual content; Robert A. Pol: conceived of the study and its design and was involved in data analysis and interpretation and writing the manuscript. Contributed to the interpretation of results and to the final adjustments to the manuscript.

Funding This study received no funding of any kind.

\section{Compliance with ethical standards}

Conflict of interest The authors of this manuscript have no conflicts of interest to disclose.

Open Access This article is distributed under the terms of the Creative Commons Attribution 4.0 International License (http://creative commons.org/licenses/by/4.0/), which permits unrestricted use, distribution, and reproduction in any medium, provided you give appropriate credit to the original author(s) and the source, provide a link to the Creative Commons license, and indicate if changes were made. 


\section{Appendix}

Visual Analog Scale (VAS-scale)

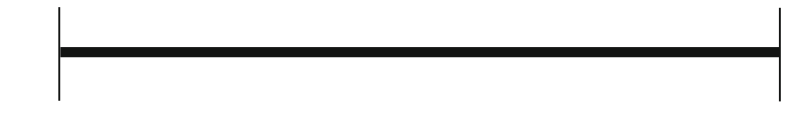

No Pain Worst imaginable pain

The Numeric Pain Rating Scale (NPRS-scale)

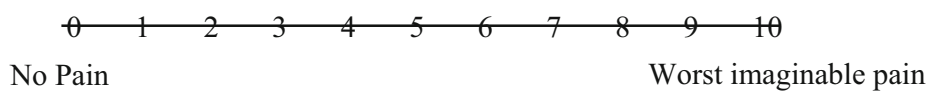

When suffering from postoperative pain after 3 months, where is the pain located most ?

General questions

- Did you undergo inguinal surgery before and/or after transplantation?

YES / NO

- Do you have Chronic Obstructive Pulmonary Disease?

YES / NO

- Do you have diabetes?

YES / NO

- Do you use painkillers and/or are you following treatment from a anaesthetist or pain

doctor?

YES / NO

\section{References}

1. Liem YS, Bosch JL, Arends LR et al (2007) Quality of life assessed with the Medical Outcomes Study Short Form 36-Item Health Survey of patients on renal replacement therapy: a systematic review and meta-analysis. Value Health 10:390-397

2. Fujisawa M, Ichikawa Y, Yoshiya K et al (2000) Assessment of health-related quality of life in renal transplant and hemodialysis patients using the SF-36 health survey. Urology 56:201-206

3. Masajtis-Zagajewska A, Pietrasik P, Krawczyk J et al (2011) Similar prevalence but different characteristics of pain in kidney transplant recipients and chronic hemodialysis patients. Clin Transplant 25:144-151
4. Wijsmuller AR, van Veen RN, Bosch JL et al (2007) Nerve management during open hernia repair. Br J Surg 94:17-22

5. Poobalan AS, Bruce J, Smith WC et al (2003) A review of chronic pain after inguinal herniorrhaphy. Clin J Pain 19:48-54

6. Van Veen RN, Wijsmuller AR, Vrijland WW et al (2007) Randomized clinical trial of mesh versus non-mesh primary inguinal hernia repair: long-term chronic pain at 10 years. Surgery 142:695-698

7. Mui WL, Ng CS, Fung TM et al (2006) Prophylactic ilioinguinal neurectomy in open inguinal hernia repair: a double-blind randomized controlled trial. Ann Surg 244:27-33

8. Wijsmuller AR, Lange JFM, Van Geldere D et al (2007) Surgical techniques preventing chronic pain after Lichtenstein hernia 
repair: state-of-the-art versus daily practice in the Netherlands. Hernia 11:147-151

9. Nielsen K, Poelman MM, den Bakker FM et al (2014) Comparison of the Dutch and English versions of the Carolinas Comfort Scale: a specific quality-of-life questionnaire for abdominal hernia repairs with mesh. Hernia 18:459-464

10. Hall WH, Ramachandran R, Narayan S et al (2004) An electronic application for rapidly calculating Charlson comorbidity score. BMC Cancer 4:94

11. Schreiber AK, Nones CF, Reis RC et al (2015) Diabetic neuropathic pain: physiopathology and treatment. World J Diabetes 6:432-444

12. Roberts MH, Mapel DW, Thomson HN (2015) The impact of chronic pain on direct medical utilization and costs in chronic obstructive pulmonary disease. Clinicoecon Outcomes Res 7:173-184

13. Hayes MHJ, Patterson DG (1921) Experimental development of the graphic rating method. Psychol Bull 18:98

14. Williamson A, Hoggart B (2005) Pain: a review of three commonly used pain rating scales. J Clin Nurs 14:798-804

15. Poobalan AS, Bruce J, King PM et al (2001) Chronic pain and quality of life following open inguinal hernia repair. Br J Surg 88:1122-1126

16. Massaron S, Bona S, Fumagalli U et al (2007) Analysis of postsurgical pain after inguinal hernia repair: a prospective study of 1,440 operations. Hernia 11:517-525

17. Lange JF, Wijsmuller AR, van Geldere D et al (2009) Feasibility study of three-nerve-recognizing Lichtenstein procedure for inguinal hernia. Br J Surg 96:1210-1214

18. Wijsmuller AR, Lange JF, Kleinrensink GJ et al (2007) Nerveidentifying inguinal hernia repair: a surgical anatomical study. World J Surg 31:414-420. doi:10.1007/s00268-006-0376-y
19. Izard G, Gailleton R, Randrianasolo R et al (1996) Treatment of inguinal hernias by Mc Vay's technique. Apropos of 1332 cases. Ann Chir 50:755-766

20. Alfieri S, Rotondi F, Di Giorgio A et al (2006) Influence of preservation versus division of ilioinguinal, iliohypogastric, and genital nerves during open mesh herniorrhaphy: prospective multicentric study of chronic pain. Ann Surg 243:553-558

21. Picchio M, Palimento D, Attanasio U et al (2004) Randomized controlled trial of preservation or elective division of ilioinguinal nerve on open inguinal hernia repair with polypropylene mesh. Arch Surg 139:755-758

22. Ravichandran D, Kalambe BG, Pain JA (2000) Pilot randomized controlled study of preservation or division of ilioinguinal nerve in open mesh repair of inguinal hernia. Br J Surg 87:1166-1167

23. Chen DC, Hiatt JR, Amid PK (2013) Operative management of refractory neuropathic inguinodynia by a laparoscopic retroperitoneal approach. JAMA Surg 148:962-967

24. Shoeibi G, Babakhani B, Mohammadi SS (2009) The efficacy of ilioinguinal-iliohypogastric and intercostal nerve co-blockade for postoperative pain relief in kidney recipients. Anesth Analg 108:330-333

25. Nourbala MH, Hollisaaz MT, Nasiri M et al (2007) Pain affects health-related quality of life in kidney transplant recipients. Transpl Proc 39:1126-1129

26. Okifuji A, Hare BD (2015) The association between chronic pain and obesity. J Pain Res 8:299-408

27. Fränneby U, Sandblom G, Nordin P et al (2006) Risk factors for long-term pain after hernia surgery. Ann Surg 244:212-219 